\title{
Ashkenazi Jew
}

National Cancer Institute

\section{Source}

National Cancer Institute. Ashkenazijew. NCI Thesaurus. Code C17950.

Ashkenazi Jews, also called Ashkenazim, are Jews who are descendants of Jews from Germany, Poland, Austria and Eastern Europe. 